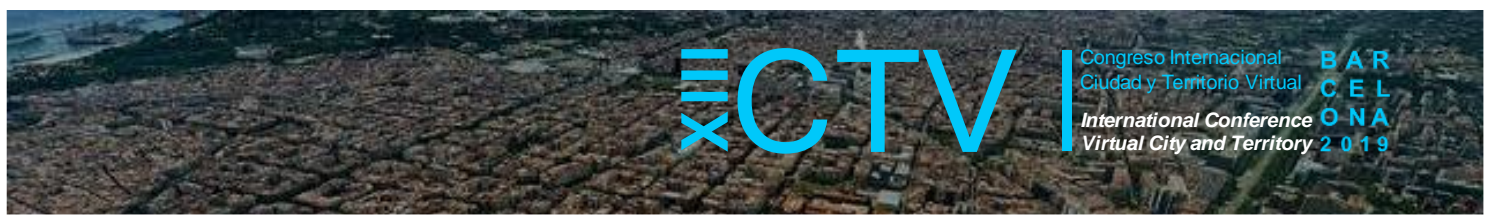

\title{
LA INFRAESTRUCTURA VERDE COMO HERRAMIENTA DE MITIGACION Y ADAPTACION URBANA EN LA CIUDAD DE SANTO DOMINGO, REPÚBLICA DOMINICANA
}

\author{
Rojas-Cortorreal, Gilkauris ${ }^{1 *}$; Peña, Julio ${ }^{2}$; Roset, Jaume ${ }^{3}$ y García, Alison ${ }^{4}$ \\ Remisión inicial: 2019-06-16; Remisión definitiva: 2019-10-24; Publicación: 2019-12-21
}

Citación: Rojas-Cortorreal, G. et al. (2019). La infraestructura verde como herramienta de mitigación y adaptación urbana en la ciudad de Santo Domingo, República Dominicana. En XIII CTV 2019 Proceedings: XIII International Conference on Virtual City and Territory: "Challenges and paradigms of the contemporary city": UPC, Barcelona, October 2-4, 2019. Barcelona: CPSV, 2019, p. 8672. E-ISSN 2604-6512. DOI http://dx.doi.org/10.5821/ctv.8672

\section{Resumen}

El calentamiento global es un hecho inequívoco, afectando de forma creciente los ecosistemas de todo el planeta, con el consiguiente incremento de los eventos singulares (olas de calor, inundaciones torrenciales, sequias, vendavales, entre otros). El Cambio Climático (CC), además, se ve reforzado en las ciudades por la presencia de fenómenos como la Isla de Calor Urbana, la contaminación atmosférica, la impermeabilización del suelo o el bajo albedo.

En este sentido es fundamental repensar de forma radical el modelo de desarrollo urbano heredado históricamente, promoviendo la reducción de la emisión de gases efecto invernadero. Asimismo, es necesario conocer los efectos del CC sobre la población y desarrollar metodologías conducentes a mejorar las condiciones ambientales mediante la adaptación de las ciudades al Cambio Climático y la reducción de sus efectos sobre la población, tanto desde la Planificación territorial, como desde el diseño urbano.

Por consiguiente, el objetivo de esta investigación es la evaluación de los aumentos de temperatura en los últimos veinte y cuatro años en la ciudad de Santo Domingo (República Dominicana), permitiendo determinar las zonas más vulnerables para determinar estrategias de mitigación y adaptación a través de la infraestructura verde.

La metodología implementada es la recolección de datos meteorológicos y urbanos de la ciudad, obtenidos los datos se realiza una evaluación de la información permitiendo determinar las épocas del año y áreas urbanas más vulnerables en la ciudad. Estas áreas de mayor vulnerabilidad son las principales a determinar estrategias de mitigación y adaptación a través de la infraestructura verde.

Los resultados obtenidos muestran que en la ciudad de Santo Domingo se percibe un aumento constante de temperatura que está íntimamente ligado a determinados fenómenos ambientales que se ha estado presentando en los últimos años (sequia, lluvias, entre otros). Este aumento se percibe mayormente en las áreas de la ciudad donde es más escasa la vegetación y permeabilidad urbana, generando inundaciones en épocas de lluvia entre otras aflicciones. Se genera un plan de acción para lograr una adaptación urbana en estos sectores.

\section{Abstract}

Global warming is an unequivocal fact, increasingly affecting the ecosystems of the entire planet, with the increase in the increase of singular events (heat waves, torrential floods, droughts, gales, among others). Climate Change (CC), in addition, is reinforced in the cities by the presence of phenomena such as Urban Heat Island, air pollution, soil waterproofing or low albedo.

In this sense, it is essential to radically rethink the historically inherited urban development model, promoting the reduction of greenhouse gas emissions. Likewise, it is necessary to know the effects of CC on the population and

\footnotetext{
${ }^{1}$ Docente investigadora en la Universidad Nacional Pedro Henríquez Ureña, https://orcid.org/0000-0001-9336-3481; ${ }^{2}$ Docente en la Universidad Autónoma de Santo Domingo; ${ }^{3}$ Docente del Departamento de Física en la Universidad Politécnica de Catalunya, https://orcid.org/0000-0002-0548-5524; ${ }^{4}$ Estudiante en la Universidad Nacional Pedro Henríquez Ureña. * Correo de contacto: gilkaurisrojas@gmail.com
} 


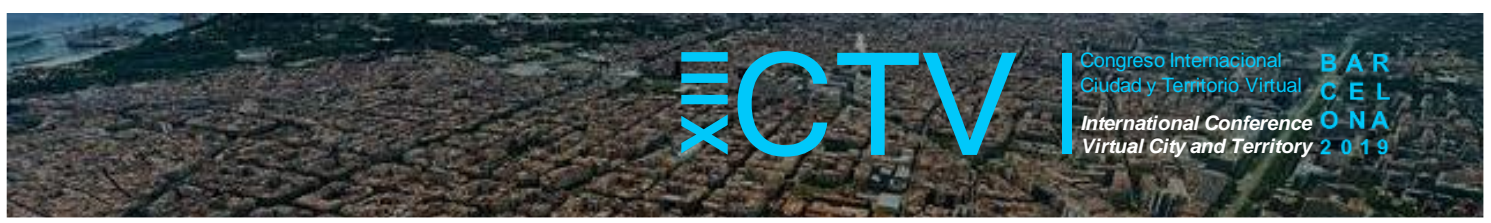

develop conducive methodologies to improve environmental conditions by adapting cities to Climate Change and reducing their effects on the population, from Territorial Planning, from urban design

The objective of this research in the evaluation of temperature increases in the last ten years in the city of Santo Domingo (Dominican Republic) will determine the most vulnerable areas to determine mitigation and adaptation strategies through green infrastructure.

The methodology implemented is the collection of meteorological and urban data of the city, the data will be an evaluation of the information that will determine the times of the year and the most vulnerable urban areas in the city. These areas of greatest modification are the main mitigation and adaptation strategies through green infrastructure.

The results obtained are that the city of Santo Domingo perceives a constant increase in temperature that is closely linked to certain environmental phenomena that have been occurring in recent years (drought, rainfall, among others). This increase is perceived mainly in the areas of the city where it lacks vegetation and urban permeability, generating floods in times of rain among other afflictions. An action plan is generated to achieve urban adaptation in these sectors.

Palabras Clave: temperatura del aire; isla de calor urbano; crecimiento urbano; cambio climático

Key words: air temperature; urban heat island; urban growth; climate change

\section{Introducción}

La República Dominicana está ubicada en el Mar Caribe, es la segunda en dimensión de las Antillas Mayores, su capital es Santo Domingo, ubicada en los $18^{\circ} 28^{\prime} \mathrm{N}, 69^{\circ} 57^{\prime}$ O, una ciudad de 3,339,410 habitantes, según el censo del 2010, esto es el 35\% del total de la población del país. Tiene una superficie de 1,393.8 km2. A partir del 2002 se dividió en el Distrito Nacional y la provincia de Santo Domingo. Es una ciudad que se encuentra básicamente a nivel del mar, con una pequeña elevación en la dirección sur-norte. La ciudad ha tenido un crecimiento poblacional exorbitante, y consecuentemente el desarrollo urbano se ha comportado de igual manera. En 1970 la población de la ciudad era a penas de 817,067 y 40 años después (2010) la población había aumentado a 3.3 millones de personas, esto equivale a multiplicarse por 4 en este período. En este trabajo intentamos descubrir el impacto que generó el crecimiento urbano que se produjo como consecuencia de ese crecimiento poblacional.

Para estos fines estudiamos el comportamiento, durante 24 años, de elementos climáticos como temperatura máxima, media y mínima, humedad relativa y precipitación. El estudio se centró en un área específica de la ciudad, el Polígono Central, por ser la más impactada por el desarrollo urbano y económico. Los datos climáticos empleados provienen de una estación meteorológica ubicada dentro de esta zona. Al estudiar el desarrollo urbano generado en el período de estudio se puso especial énfasis en la pérdida del arbolado urbano, por la influencia que el mismo tiene sobre el confort climático de la ciudad.

Para hacer el estudio de las variaciones climáticas se dividió en trienio el periodo de estudios, 1995-2018, para así poder dar un seguimiento más cercano a los posibles cambios que se presentaran. También se correlacionó las variaciones climáticas detectadas, además de con el desarrollo urbano, con los fenómenos atmosféricos ocurridos en los años de estudios, tales como tormentas tropicales y huracanes, para descartar la influencia de los mismos en las variaciones climáticas que se fueron detectando. La metodología desplegada a lo largo de esta investigación nos permitió detectar que la ciudad de Santo Domingo de hoy es en promedio entre 0.8 y $1.5 \stackrel{\circ}{\circ}$ más calurosa que aquella de 1995 , y las evidencias parecen indicar que este 


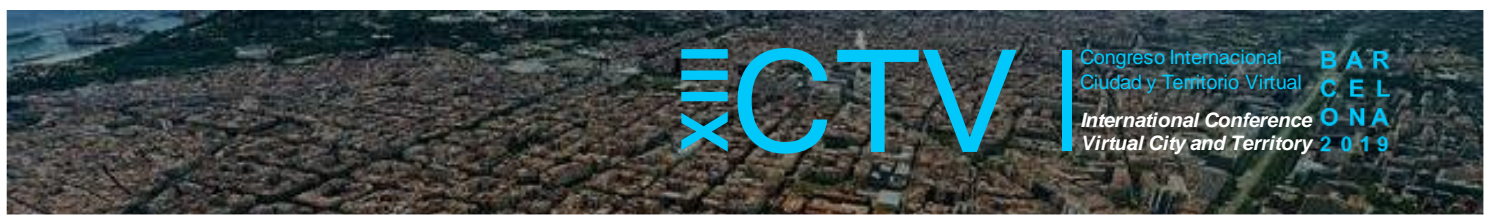

incremento de temperatura está vinculada al desarrollo urbano de la ciudad y a la pérdida del arbolado, como consecuencia derivada del propio desarrollo.

Hemos realizado estudios previos sobre la temperatura y la influencia del arbolado en la mejora de las condiciones de confort en el espacio urbano (López-Ordóñez, Roset, \& Rojas-Cortorreal, 2017; Rojas-cortorreal, Navés, Peña, Roset, \& López-ordóñez, 2017; Rojas Cortorreal, 2016; Rojas Cortorreal, Roset, \& Navés, 2016). Igualmente existen estudios previos relacionados con el estudio del aumento de la temperatura a nivel urbano (isla de calor urbana) y los factores que la determinan, ya que este fenómeno incide grandemente en los objetivos planteados para la Objetivos de Desarrollo Sostenible (ODS) (CEPAL \& ONU, 2016; Garcia-Nevado, PagesRamon, \& Coch, 2016; Masoud, Beckers, \& Coch, 2016; Salvati, 2016; Salvati, Coch, \& Cecere, 2014, 2015; Salvati et al., 2015; Sosa, Correa Cantaloube, \& Cantón, 2017).

\section{Metodología}

Para la evaluación de las variaciones de la temperatura en la ciudad de Santo Domingo y las variables que han influido en este cambio se implementó una metodología de recolección de datos y evaluación de los mismos que nos permita obtener conclusiones. La metodología implementada en esta investigación es la siguiente:

- Selección de área de estudio de la ciudad de Santo Domingo

- Recopilar y evaluar los datos meteorológicos de los últimos 24 años

- Levantamiento de los cambios a nivel urbano y arbolado en la ciudad durante este periodo

- Correlacionar el comportamiento de los datos climáticos con las intervenciones urbanas

\subsection{Selección de área de estudio de la ciudad de Santo Domingo}

La ciudad de Santo Domingo está dividida política y administrativamente en ocho sectores los cuales son: Distrito Nacional, Santo Domingo Norte, Santo Domingo Este, Santo Domingo Oeste, Los Alcarrizos, Boca chica, Pedro Brand y San Antonio de Guerra.

Figura 1. División político-administrativa de la ciudad de Santo Domingo, República Dominicana

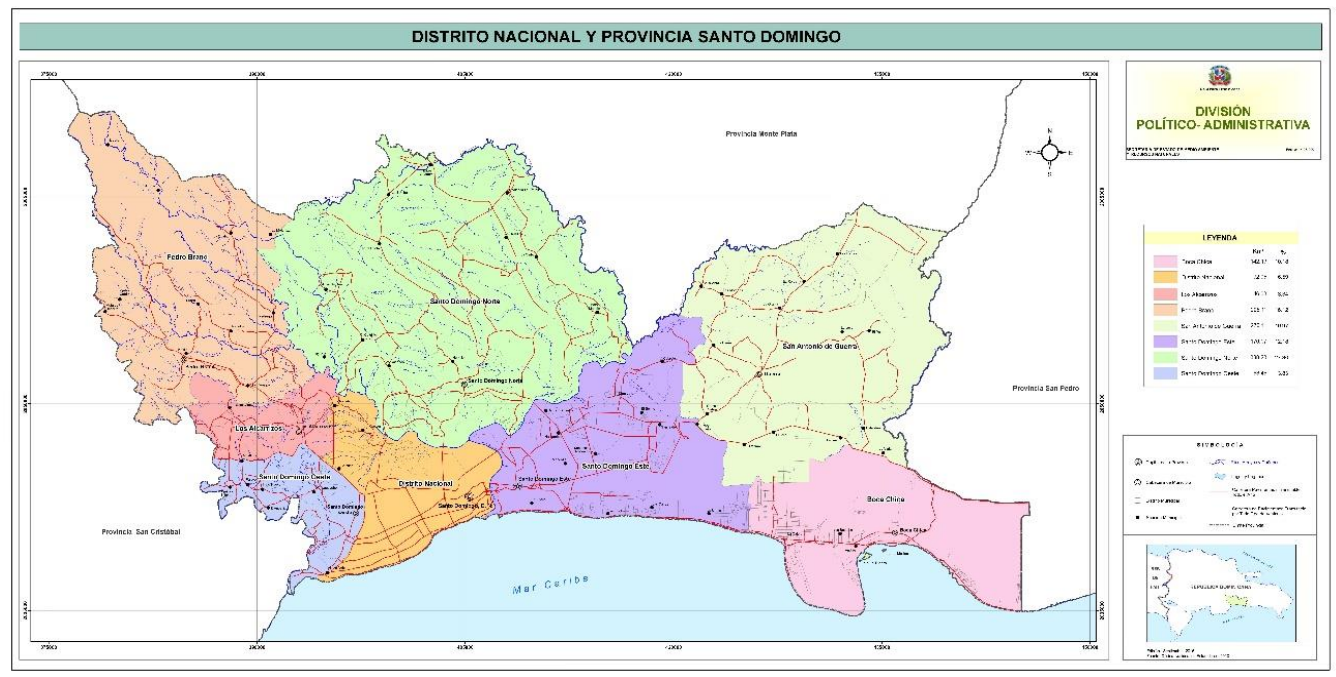

Fuente: Oficina Nacional de Estadísticas y Ministerio de Medio Ambiente y Recursos Naturales. 


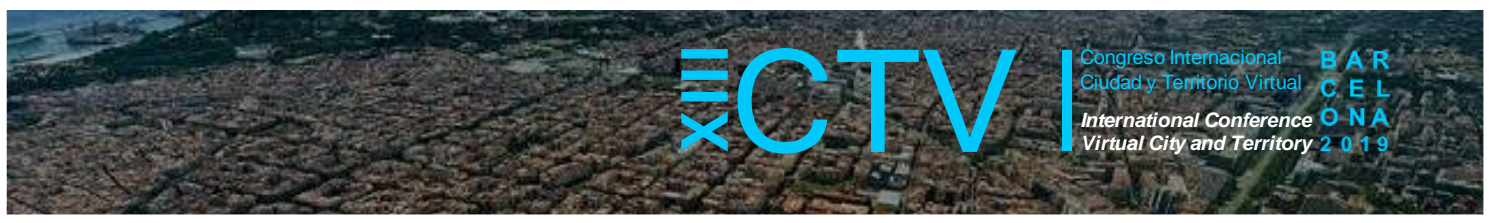

El área de estudio es el Distrito Nacional, ya que es el centro de actividad socio-económica y cultural de la ciudad, convirtiéndola el centro principal de la ciudad. El Distrito Nacional cuenta con un área de $92.05 \mathrm{~km} 2$ (6.59\% del área de la ciudad). Dentro del Distrito Nacional está el llamado Polígono Central, un área de $2.77 \mathrm{Km} 2$ que concentra el mayor desarrollo económico y urbano de todo el Distrito Nacional. Los planos presentados fueron suministrados por el Ayuntamiento de Santo Domingo (ADN, 2019).

La ciudad de Santo Domingo ha sufrido un sin número de intervenciones a nivel urbano e igualmente un alto crecimiento poblacional que está estrechamente vinculado al aumento de densidad de edificaciones, siendo estas variables uno de los principales elementos de enfoque en la investigación.

Figura 2. Plano general del Distrito Nacional

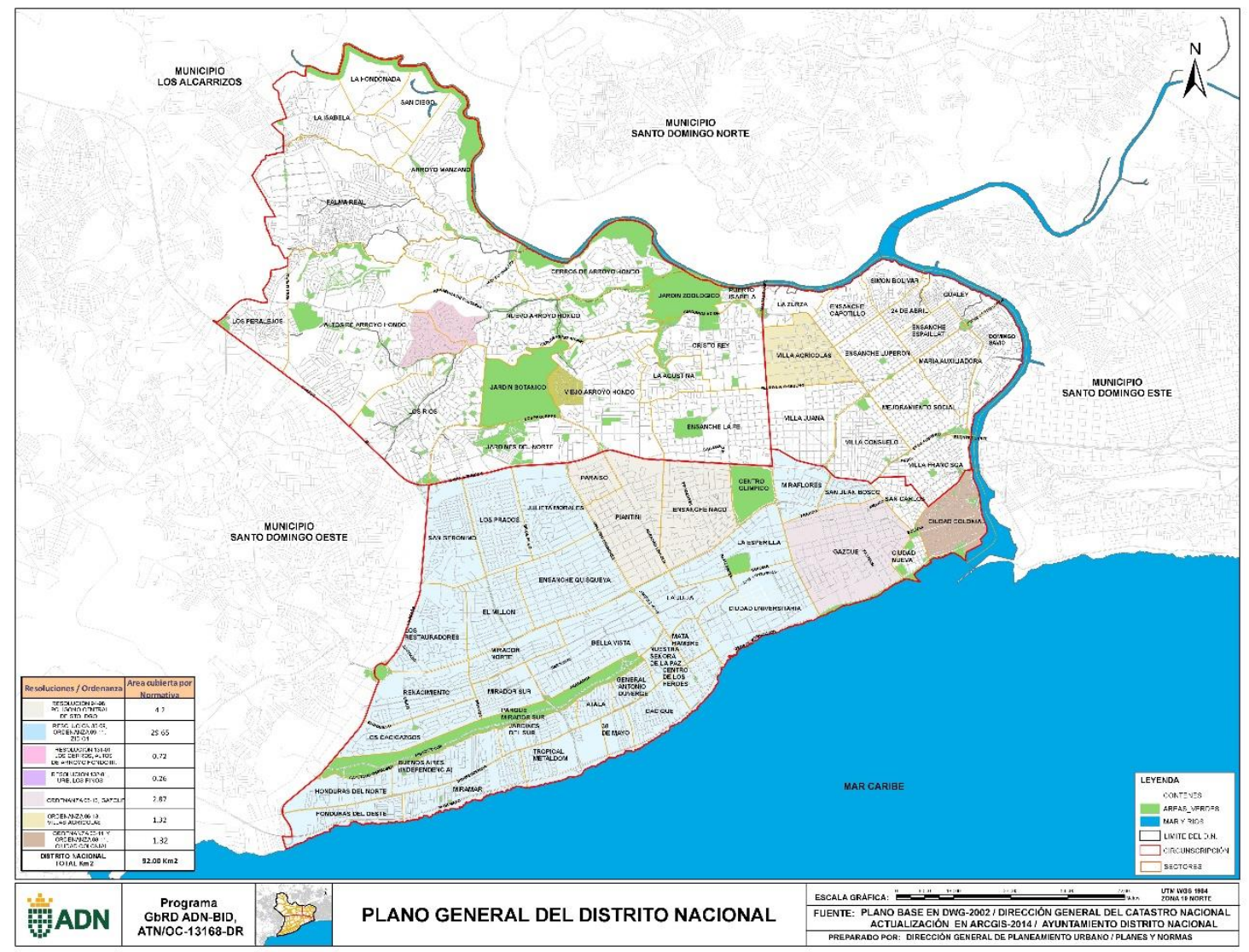

Fuente: Ayuntamiento del Distrito Nacional (ADN, 2019).

\subsection{Recopilar y evaluar los datos meteorológicos de los últimos 24 años}

La ciudad de Santo Domingo ha vivido una evolución tanto a nivel de crecimiento de la ciudad como a nivel de intervenciones urbanas, para poder evaluar como esta evolución ha influido climáticamente en la ciudad, se realizará un levantamiento de datos de más de dos décadas (24 años). Por lo que el alcance del levantamiento y evaluación de datos será desde el año 1995 hasta el 2018. 


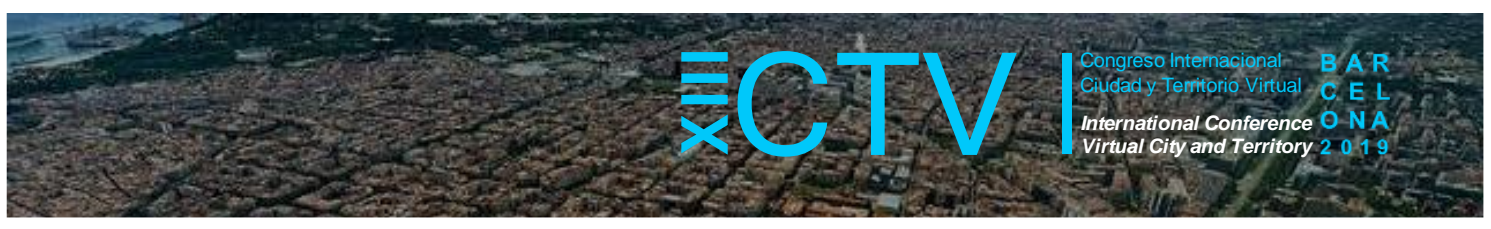

Se realizó un levantamiento de datos de temperatura (máxima, mínima y media), precipitación, humedad relativa, dirección y velocidad del viento. Estos datos se obtuvieron de la Oficina Nacional de Meteorología (Oficina Nacional de Meteorologia (ONAMET), 2019), la estación meteorológica que suministra los datos está localizada en el Polígono Central de la ciudad en la avenida Tiradentes esquina Calle Lic. Carlos Sánchez en la torre Edesur Dominicana².

Figura 3. Localización de la estación Meteorológica

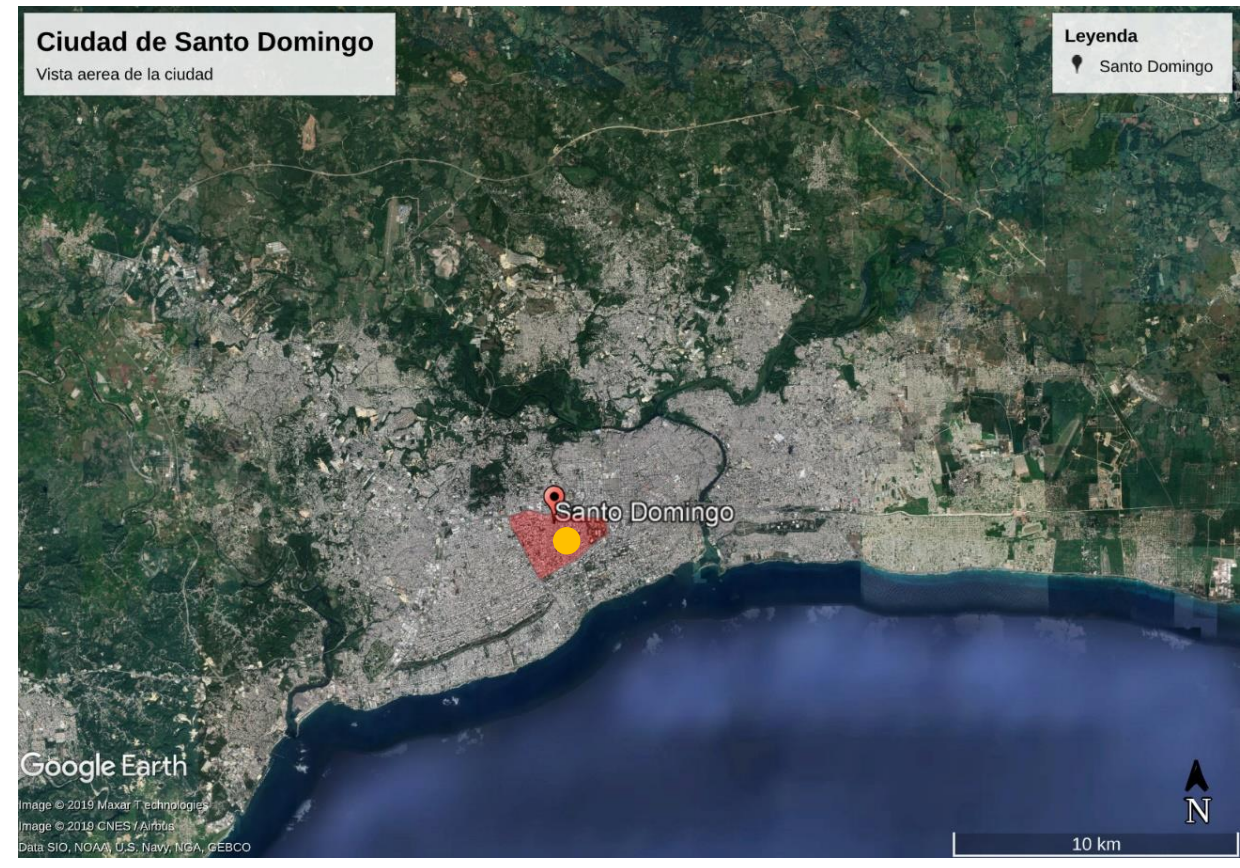

Leyenda

Polígono central Ubicación estación meteorológica

Fuente: Google Earth.

Recopilados los datos se realizó un análisis a nivel macro y micro climático, para poder evaluar las variaciones o evolución de los datos, se tomó como año tipo el año 1995. Seleccionado el año tipo (modelo), se procedió a una subdivisión de los años en trienios para comparar y determinar las variaciones que se fueron registrando en esos periodos.

Figura 4. Distribución de los años en trienio

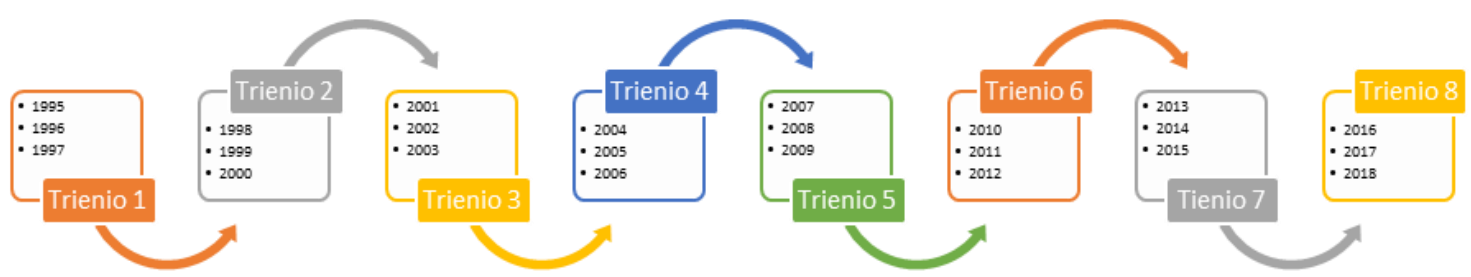

Fuente: elaboración propia.

\footnotetext{
${ }^{2}$ Edesur Dominicana, S.A., es una de las empresas estatales distribuidoras de electricidad de República Dominicana.
} 


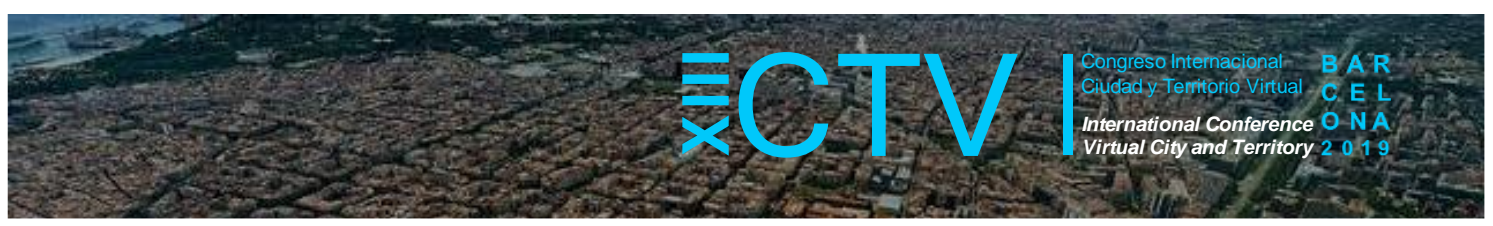

Subdividido los años se evaluó independientemente cada trienio permitiendo comparar las variaciones anuales entre los indicadores climáticos. Determinadas las conclusiones se procedió a una evaluación macro de los resultados permitiendo determinar las conclusiones generales.

Eventualmente se tomó en cuenta en el análisis los fenómenos atmosféricos ocurridos en estos años, ya que los mismos afectan directamente al clima por nuestra condición de isla, clima cálido húmedo y además estar en la ruta de los huracanes del caribe.

\subsection{Levantamiento de los cambios a nivel urbano y arbolado en la ciudad durante este periodo}

Las principales variables que afectan el clima en la actualidad están directamente relacionadas con las acciones del hombre sobre su entorno. Por este motivo, se ha tomado en cuenta los indicadores de crecimiento urbano, intervenciones urbanas e intervención en las áreas verdes de la ciudad. Se realizará un levantamiento de datos de las intervenciones y crecimiento urbano de la ciudad durante este periodo (1995-2018). Permitiendo determinar cuáles han sido de gran impacto para la ciudad, generando afecciones a largo plazo en la misma.

\subsection{Correlacionar el comportamiento de los datos climáticos con las intervenciones urbanas}

Evaluada las temperaturas y determinado los acontecimientos a nivel urbano relevantes para la ciudad, se realiza una correlación a través de los años con de los datos de temperatura versus las intervenciones urbanas. Este análisis permitirá determinar aquellas intervenciones que han aportado o afectado directamente el clima de la ciudad a largo plazo.

\section{Resultados}

\subsection{Análisis de datos climáticos}

Para el análisis de las temperaturas se subdividieron los años en trienios, a través de este método evaluar y comparar el comportamiento de la temperaturas mínima, máxima y media. Se puede apreciar en las gráficas las estaciones marcadas, igualmente los años con fenómenos atmosféricos ocurridos en ese rango.

En el primer trienio (1995-1997) las temperaturas tienen un comportamiento similar cada año. Los datos registraron temperaturas máximas de $32^{\circ} \mathrm{C}$ y temperaturas mínimas de $30^{\circ} \mathrm{C}$. Las temperaturas máximas registran valores de acorde al clima. No obstante, se presentaron temperaturas mínimas muy variantes en la primavera de esos tres años. En la temperatura mínima del año 1997 se puede apreciar un ligero aumento de $0.3^{\circ} \mathrm{C}$ en relación a los demás años.

En el segundo trienio (1998-2000) las temperaturas máximas fueron de $33^{\circ} \mathrm{C}$ y mínimas de $29^{\circ} \mathrm{C}$. Las temperaturas máximas registradas no sobre pasaron los $33^{\circ} \mathrm{C}$. Sin embargo, se registraron cambios de aumento de temperatura de hasta $0.5^{\circ} \mathrm{C}$ en las temperaturas mínimas. 


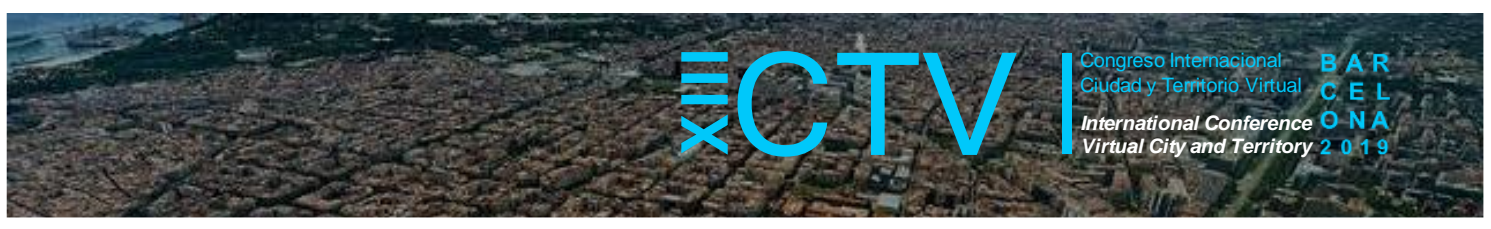

En ambos trienios las temperaturas máximas registradas fueron en las épocas de verano, comportamiento esperado para estas épocas del año (verano), en un clima tropical (cálido húmedo).

Figura 5. Gráficas de las temperaturas del aire de los trienios 1 y 2

Trienio 1

Trienio 2
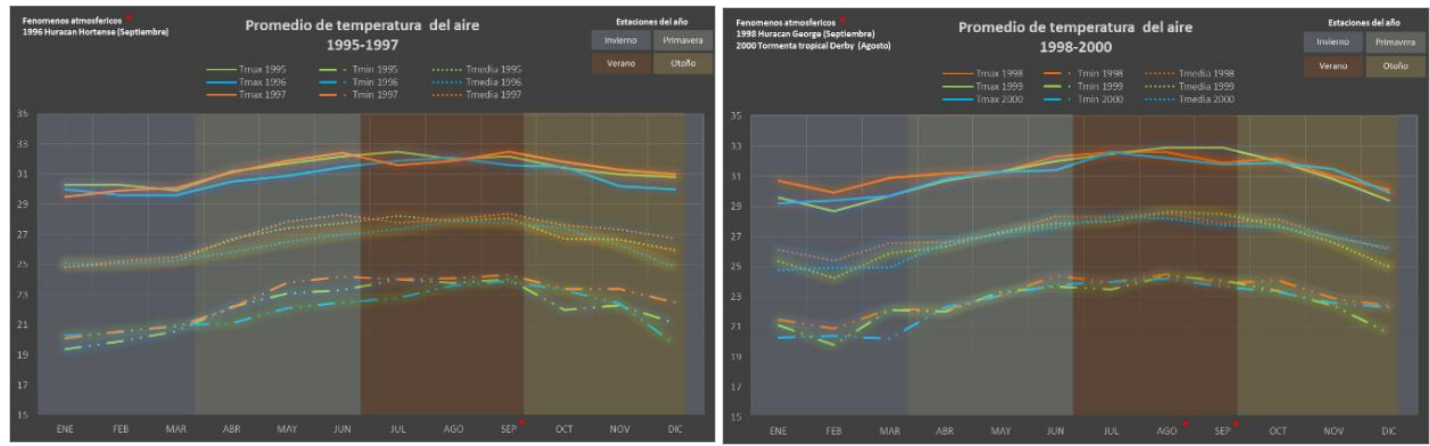

Fuente: Elaboración propia en base a los datos de la Oficina Nacional de Meteorología.

En el tercer trienio (2001-2003) se puede apreciar un comportamiento similar entre los datos registrados cada año. Durante este tercer trienio las temperaturas promedio registradas fueron temperaturas máximas de $32^{\circ} \mathrm{C}$ y temperaturas mínimas de $30^{\circ} \mathrm{C}$. Las temperaturas mínimas registraron un aumento de hasta $0.7^{\circ} \mathrm{C}$.

En el cuatro trienio (2004-2006) se puede apreciar que cada año tuvo un comportamiento totalmente distinto, para el año 2005 en la época de verano se registró un pico permitiéndonos apreciar el aumento de hasta $1^{\circ} \mathrm{C}$ de la temperatura máxima en el mes de agosto en comparación a otros años. La temperatura mínima se registró un aumento de hasta $0.9^{\circ} \mathrm{C}$ en el año 2006. Las temperaturas promedio registradas fueron temperaturas máximas de $33^{\circ} \mathrm{C}$ y temperaturas mínimas de $30^{\circ} \mathrm{C}$

Figura 6. Gráficas de las temperaturas del aire de los trienios 3 y 4

Trienio 3

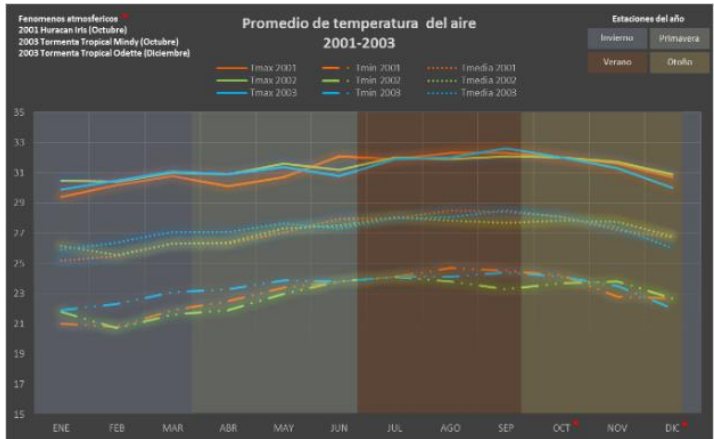

Trienio 4

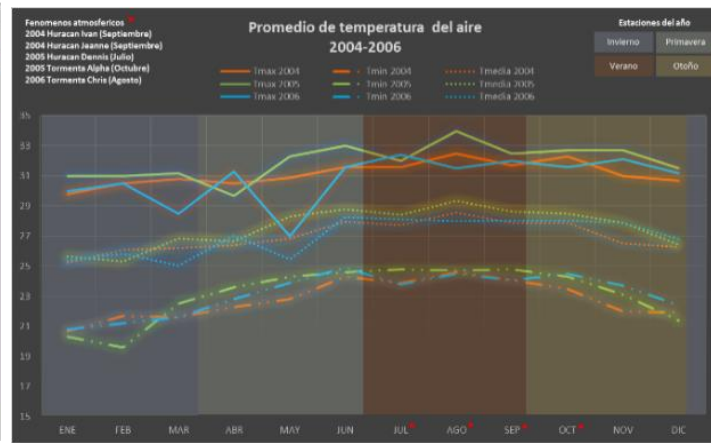

Fuente: Elaboración propia en base a los datos de la Oficina Nacional de Meteorología.

En el quinto y sexto trienio las temperaturas tomaron un rumbo totalmente distinto en comparación a otros trienios. En el quinto trienio (2007-2009) se registraron aumento de temperaturas máximas y mínimas en los meses de las estaciones de primavera y verano. Las temperaturas máximas registraron un aumento de hasta $1.6^{\circ} \mathrm{C}$ en el mes de mayo en el año 2009 y las temperaturas mínimas registraron un aumento de hasta $1.2^{\circ} \mathrm{C}$ en verano del año 


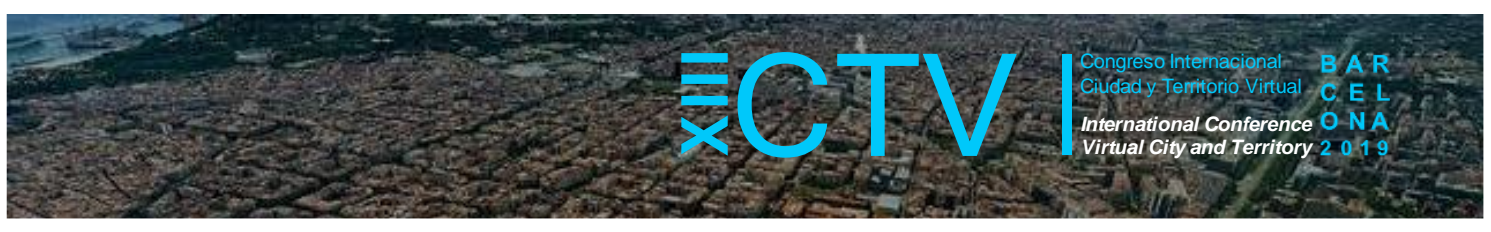

2009. Igualmente, se registraron temperaturas mayores en otoño de este mismo año. Las temperaturas promedio registradas fueron temperaturas máximas de $33^{\circ} \mathrm{C}$ y temperaturas mínimas de $29^{\circ} \mathrm{C}$.

En el 2010 aunque se registraron aumentos de temperaturas máximas en el mes de septiembre. Las temperaturas mínimas de ese mismo año, registraron un aumento de hasta $1.6^{\circ} \mathrm{C}$ en las estaciones de primavera, verano y otoño. Este mismo comportamiento se registró en el año 2012, temperaturas máximas algo elevadas, sin embargo, la temperatura mínima son las más afectas en cuanto aumento se refiere.

Figura 7. Gráficas de las temperaturas del aire de los trienios 5 y 6

Trienio 5

Trienio 6
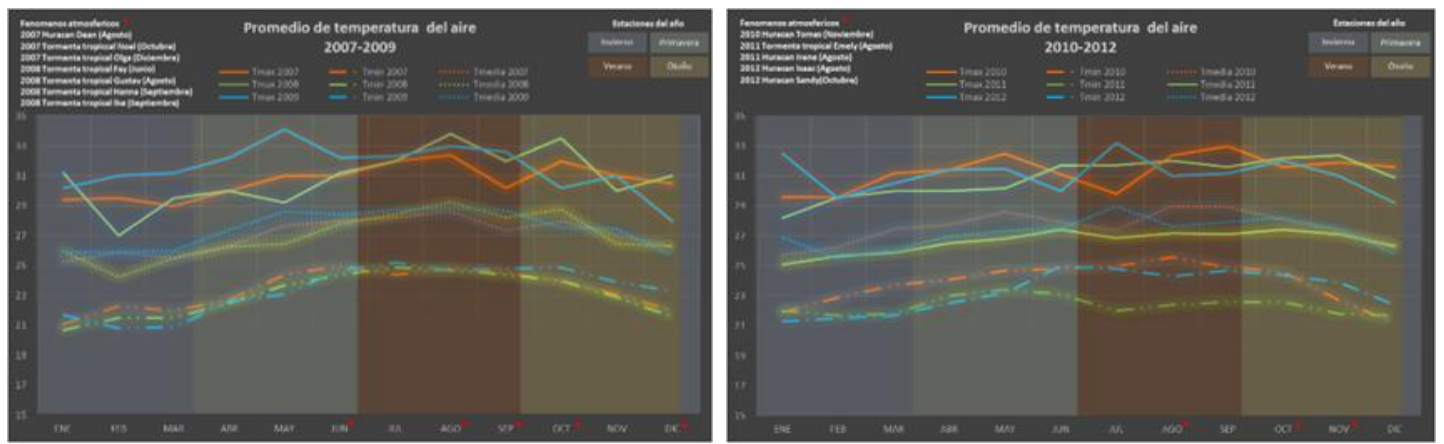

Fuente: Elaboración propia en base a los datos de la Oficina Nacional de Meteorología.

El séptimo trienio (2013-2015) podemos observar como en el año 2013 las temperaturas máximas tienen un comportamiento sin variaciones significativa según la estación correspondiente, sin embargo, al observas las temperaturas mínimas estas registran un aumento de hasta $1.6^{\circ} \mathrm{C}$ en las estaciones de verano y otoño. Para el año 2014 el mismo fenómeno se puede apreciar, pero en este caso ampliando el periodo hasta la primavera de modo que el aumento se registró en las estaciones de primavera, verano y otoño, registrando aumento de hasta $1.5^{\circ} \mathrm{C}$. Para el año 2015 se puede observar aumentos en las temperaturas máximas para la época de verano y otoño. Por otra parte, aumentos en las temperaturas mínimas de verano, otoño e invierno.

Figura 8. Gráficas de las temperaturas del aire de los trienios 7 y 8

Trienio 7

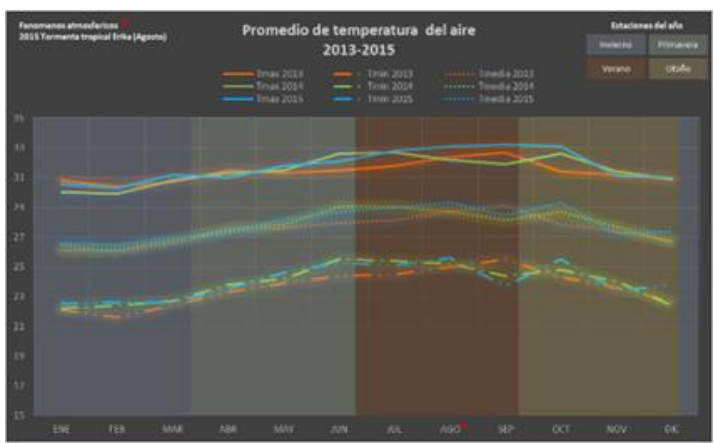

Fuente: Elaboración propia en base a los datos de la Oficina Nacional de Meteorología.
Trienio 8

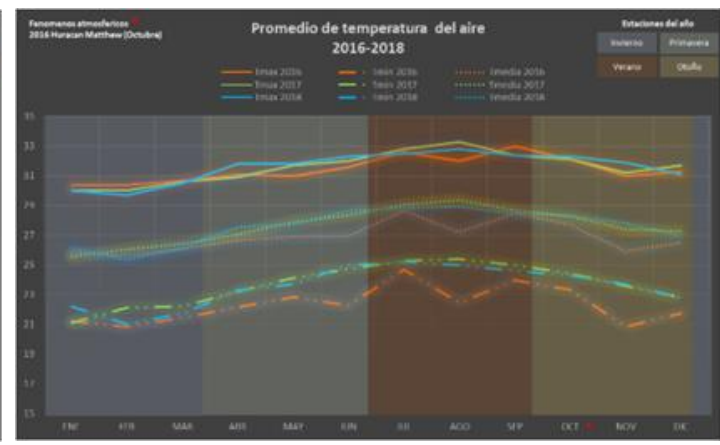

Para el octavo trienio el comportamiento de las temperaturas entre los años es similar. Para el año 2016 las temperaturas máximas y mínimas presentaron pocas variaciones. Sin embargo, 


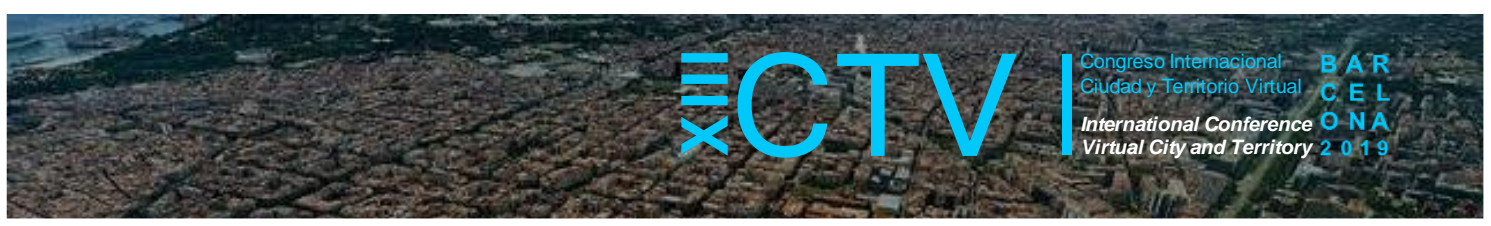

para el año 2017 estas temperaturas presentaron un aumento nuevamente. Pero esta vez con un comportamiento más homogéneo en comparación a episodios similares anteriores. Para el año 2018 se puede apreciar que las temperaturas mínimas aumentaron y continúan con el mismo comportamiento del año anterior.

\subsection{Análisis del crecimiento de la ciudad de Santo Domingo, República Dominicana}

Desde el año 1996 el país ha experimentado un importante número de cambios, a partir de las intervenciones urbanas realizadas y un aumento importante de la población. Desde una perspectiva ambiental, el crecimiento de las ciudades crea una demanda que afecta diversos factores, la Oficina Nacional de Estadística (ONE) define los siguientes indicadores: la expansión de zonas urbanas, los niveles urbanización y la densidad de poblacional (Oficina Nacional de Estadistica (ONE), 2015)(Valdez, 2015).

Para la región metropolitana se estima un total de 2,678,097 para el año 2000, la proyección realizada por la ONE estima que para el año 2030 la población metropolitana total será 4,483,519 (Oficina Nacional de Estadistica (ONE), 2009, 2016).

Figura 9. Datos y proyección de la población dominicana. Año 1981 - 2030

Datos y proyeccion de la población

1981 - 2030

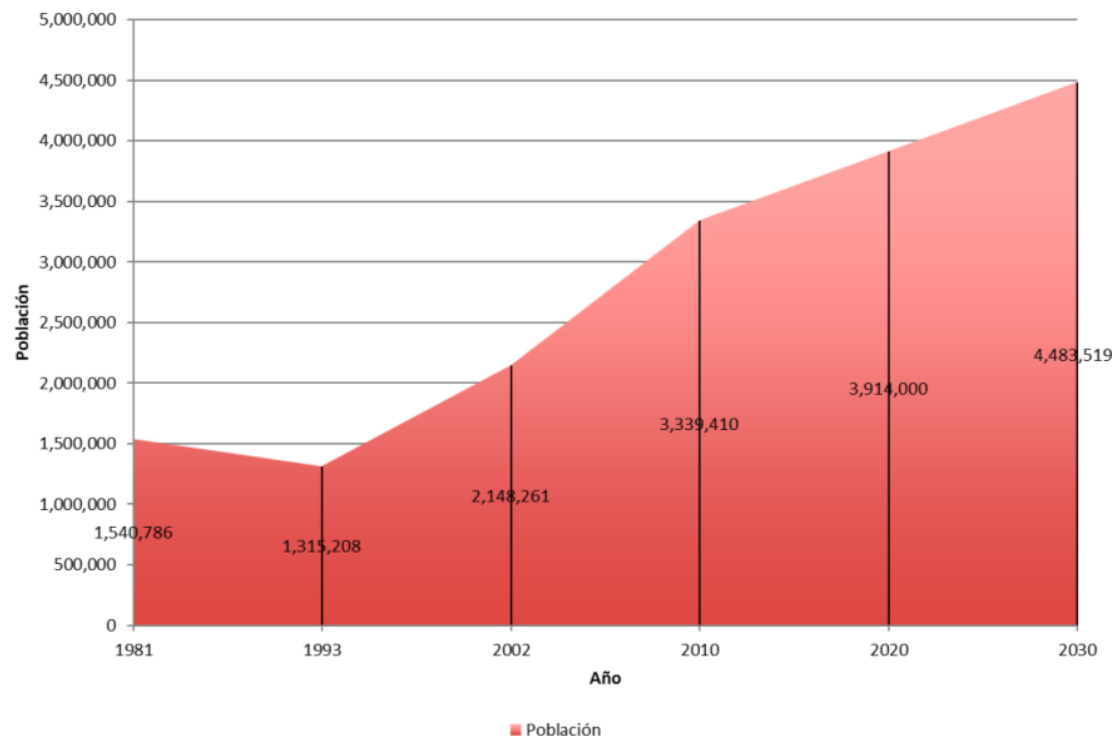

Fuente: Oficina Nacional de Estadísticas (ONE).

Este incremento poblacional genera una demanda de avances urbanísticos y de infraestructura, estas variables están estrechamente vinculadas con la forma de ordenar u organizar un territorio. La demanda para el mantenimiento de estas necesidades crea un deterioro del suelo a raíz de la ocupación, y deforestación generando lugares vulnerables a peligros ambientales y afectando directamente al ecosistema.

En la Figura 10 se puede apreciar el crecimiento que ha vivido la ciudad desde el año 1995 y como el mismo ha ido eliminando un porciento importante de áreas verdes urbanas. 


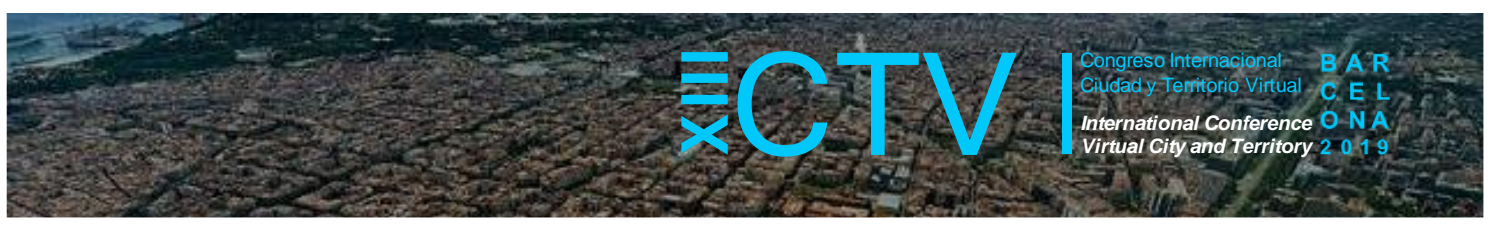

A nivel de intervención urbana, en estos veinticuatro años la ciudad ha vivido varios cambios a nivel urbano, de los cuales podemos mencionar: la construcción del Expreso 27 de febrero y del Corredor Duarte y un alto nivel de construcción de torres donde antes había casas individuales con un bajo nivel de ocupación del suelo.

Figura 10. Vista aérea del crecimiento de la ciudad de Santo Domingo desde el 1995 al 2018
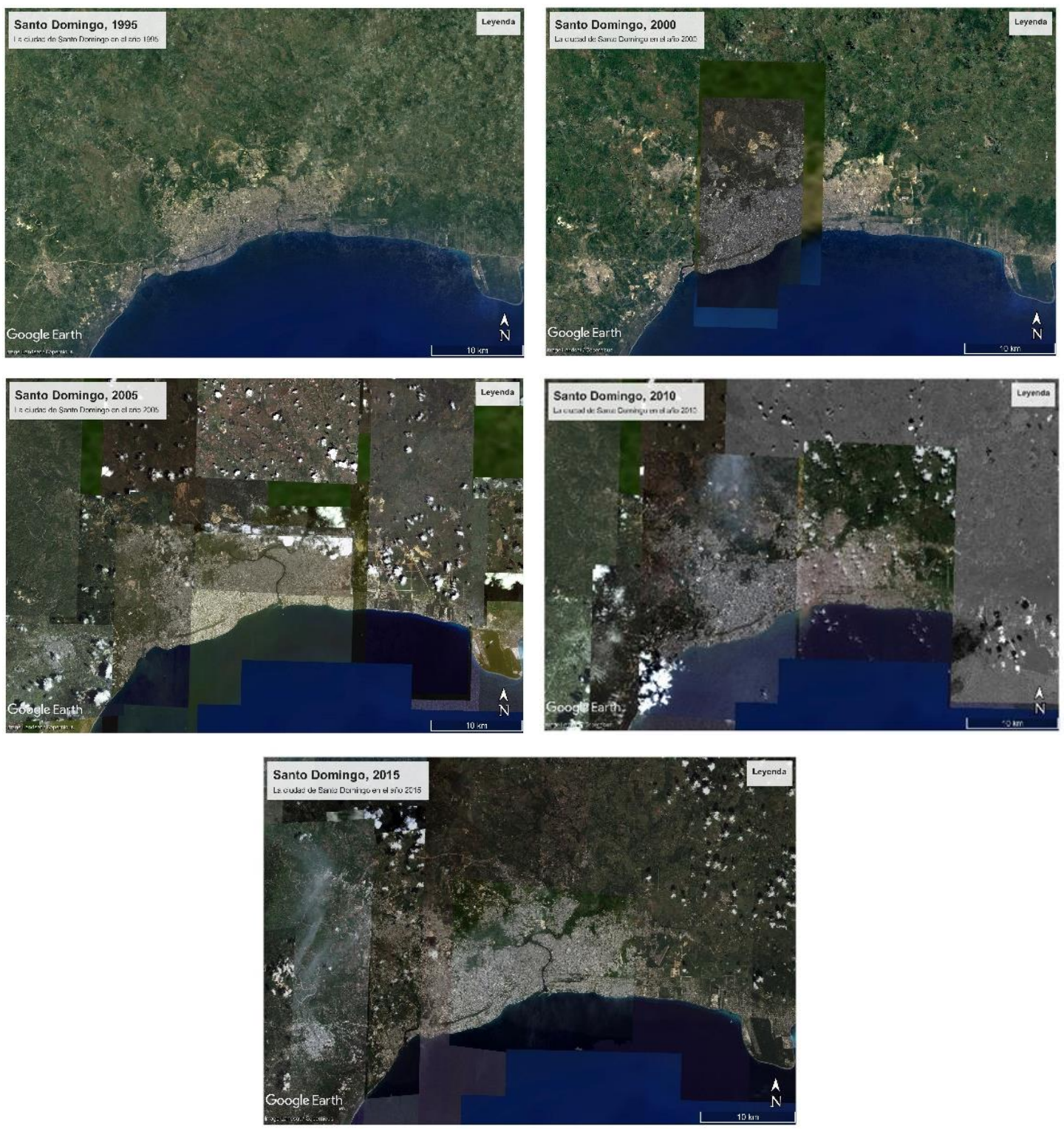

Fuente: Google Earth.

La avenida 27 de febrero es una de las vías principales de la ciudad de Santo Domingo, atravesándola totalmente en el sentido este-oeste, convirtiéndola en unas de las importantes del Distrito Nacional por ser la conexión principal entre Santo Domingo Este y Oeste. Esta avenida inicia desde el puente Juan Bosch a través del cual conecta con Santo Domingo Este hasta la autopista Duarte comunicando con Santo Domingo Oeste. Por tener un alto nivel de conectividad es unas de las vías más demandantes en cuanto transporte público-privado se refiere, por este motivo nace el interés de intervenirla para poder suplir las demandas el alto 


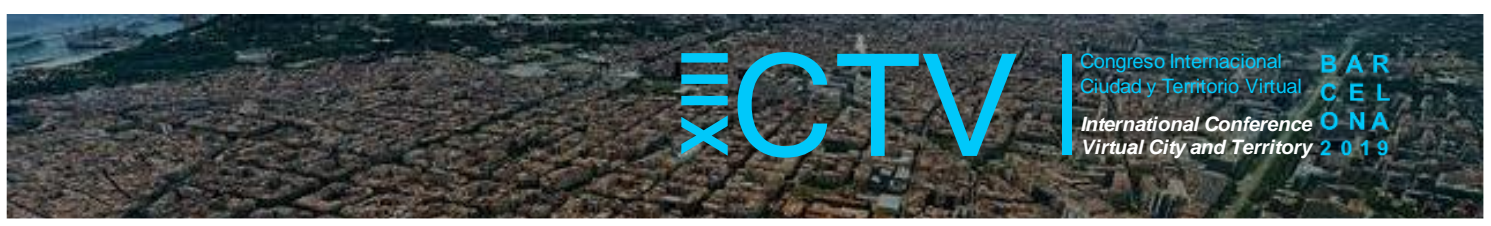

flujo vehicular que por ella circula y poder solucionar el gran número de problemáticas existentes. Esta avenida durante el gobierno del Dr. Leonel Fernández (1996 - 2000) fue intervenida con la finalidad de convertirla en un corredor expreso. Esta intervención contó con la construcción de pasos a desnivel, elevados, Bulevar, ampliación de la vía en a 10 carriles y túneles, logrando una intervención de hasta un $63 \%$ de la misma.

Figura 11. Imágenes de intervención urbana en la 27 de febrero del año 1997

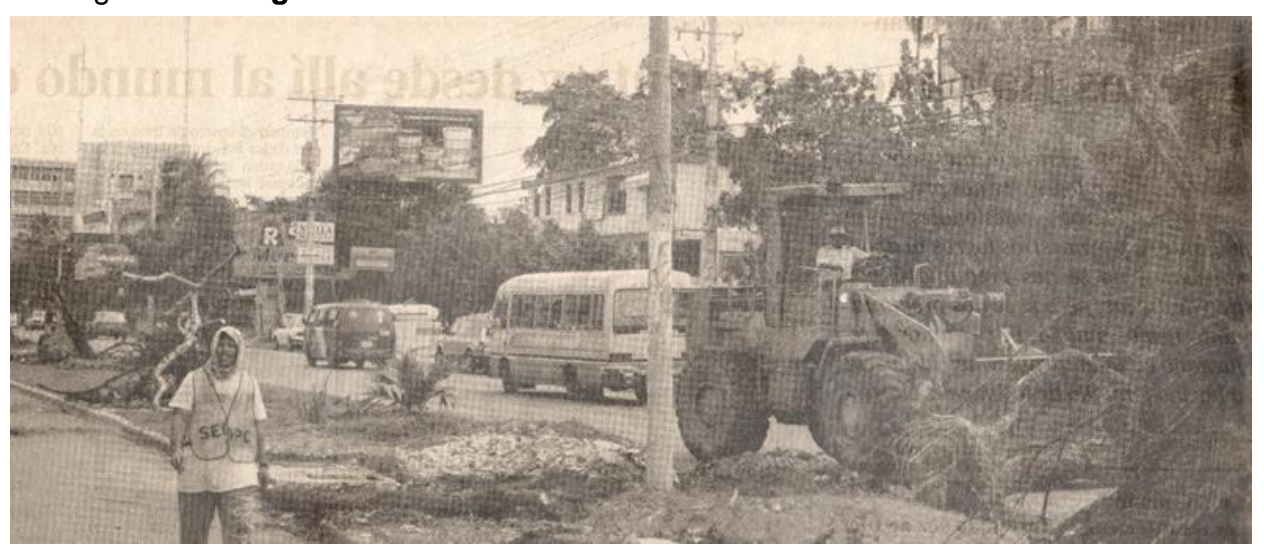

Fuente: Periódico El Siglo. Desniveles, urbanismo y concertación. Año 1997.

El Bulevar de la 27 de febrero fue inaugurado para el 29 de marzo del 1999, fue unas de las intervenciones realizadas en esta avenida. Para la construcción de este Bulevar se intervino drásticamente esta avenida, deforestando en gran medida esta área urbana.

Figura 12. Imagen de demolición de arbolado en las zonas urbanas de la ciudad. Año 1998

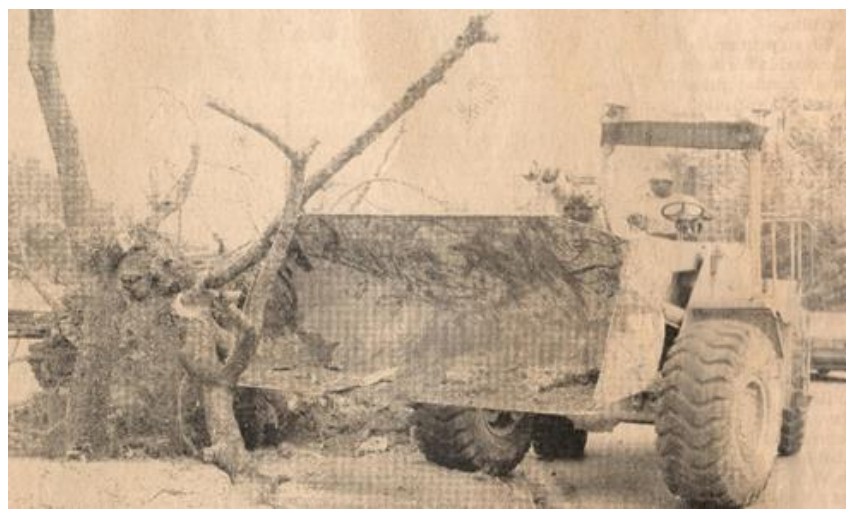

Fuente: Periódico El Siglo. Las épocas de Santo Domingo. Arq.

Igualmente, la construcción de los elevados, pasos a desnivel, túneles y la ampliación de la avenida a 10 carriles fue una intervención que afecto en varios aspectos la densidad de verde y generando a su vez un aumento del porciento de hormigón y asfalto en la ciudad. En ocasión de las excavaciones para la construcción del túnel se introdujo al país la retroexcavadora, equipo que luego fue muy útil e influyente en el desarrollo del llamado "Boom de las torres".

En el año 2011, se inauguró el Corredor Duarte construido por el Ministerio de Obras Públicas y Comunicaciones (MOPC). El Corredor Duarte se planea como solución vial para mejorar las condiciones de transito de Santo Domingo, debido al incremento que día a día vive la ciudad, conllevando a un aumento de automóvil privado y público. Este corredor consta de 6 elevados 


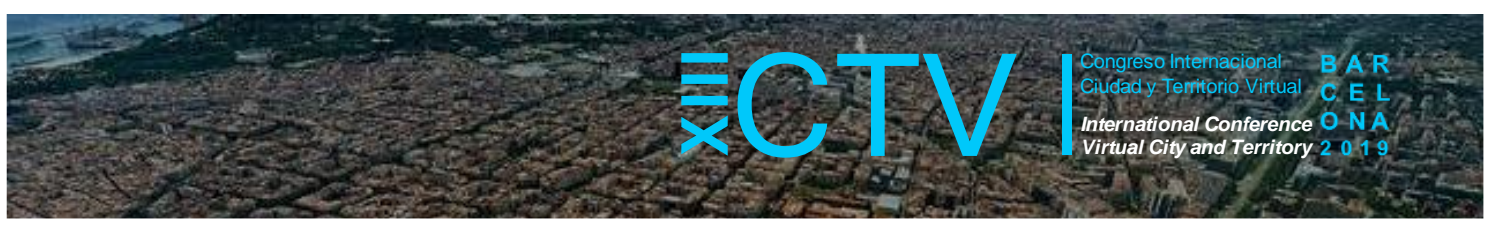

(Figura 13), distribuidos por toda la ciudad. Estos elevados se distribuyen de la siguiente manera: Av. 27 de febrero con Av. Ortega y Gasset (1), Ave. Charles de Gaulle con Autopista San Isidro (2), Ave. John F. Kennedy con Dr. Defilló (3), Ave. John F. Kennedy con Ave. Núñez de Cáceres (4), Autopista Duarte con Ave. Manoguayabo (5) y Autopista Duarte con Ave. Monumental (6).

Figura 13. Localización de los elevados en la Ciudad de Santo Domingo

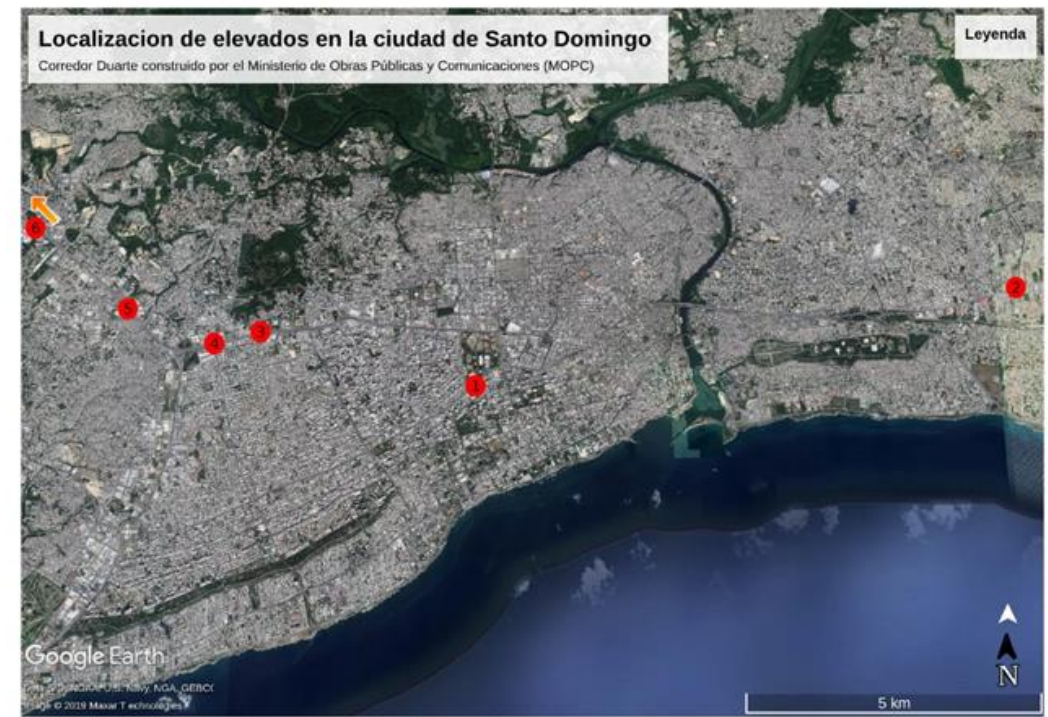

Fuente: Elaboración propia con base a Google Earth.

Para construcción de estos corredores, al igual que la intervención urbana de la 27 de febrero generó la tala de un gran porciento de áreas verde en la ciudad. Pero este porcentaje en ningún momento fue restituido nuevamente. En esta intervención urbana se sustituyó los árboles frondosos por palmeras y reemplazando el área verde en las isletas de las avenidas por hormigón armado.

Figura 14. Vista aérea de la av. 27 de febrero

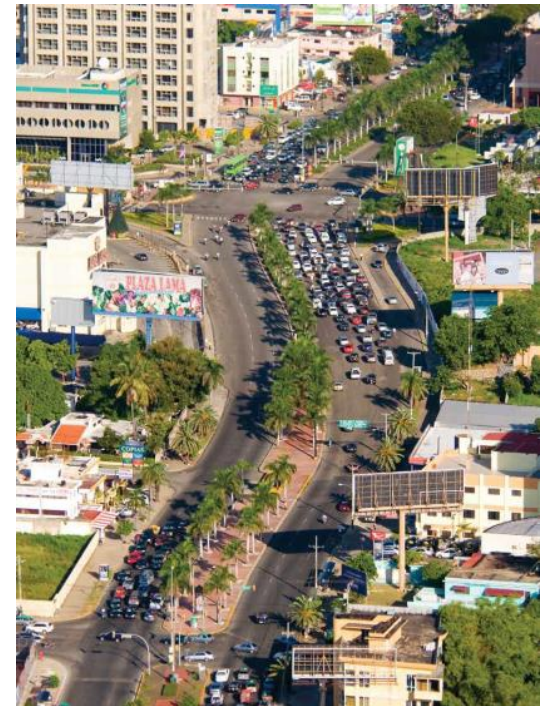

Fuente: Arboles de Santo Domingo. JICA, ADN y Intec. 


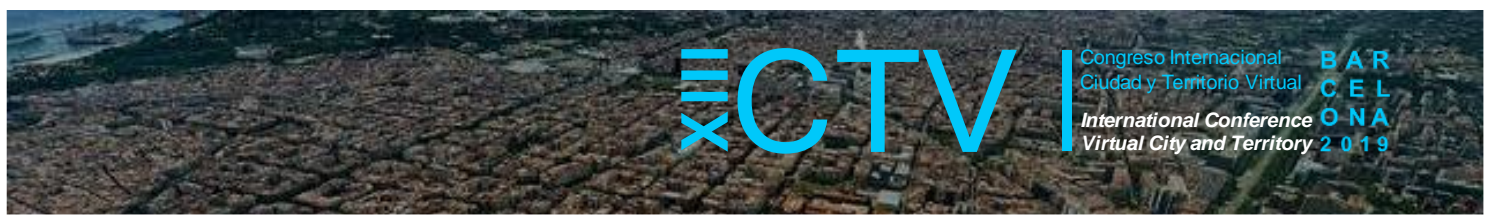

Después de acontecidos estos eventos, el siguiente y más impactante ha sido la construcción de torres de apartamentos en la ciudad. La retroexcavadora, esta herramienta afirmó su función en temas de construcción, generando el interés en inversionistas para la construcción de edificios de gran altura, ya que permitía hacer grandes excavaciones en la dura roca del suelo de Santo Domingo, lo cual permitió soterrar los estacionamientos y rentabilizar el costo de la tierra, en detrimento del verde de la ciudad que se encontraba en los jardines y patios de las casas que ahora se convertían en edificaciones en altura.

El sector que atrajo más la atención para esta construcción fue el Ensanche Naco por los grandes lotes que tenían las viviendas. Estas construcciones aumentaron el nivel de hormigón a nivel urbano y disminución en gran medida de áreas verdes, generando un incremento en elementos de captación de temperaturas creando aportaciones significativas al fenómeno de la isla de calor urbano.

Figura 15. Imágenes de la ciudad de Santo Domingo. Año 2018
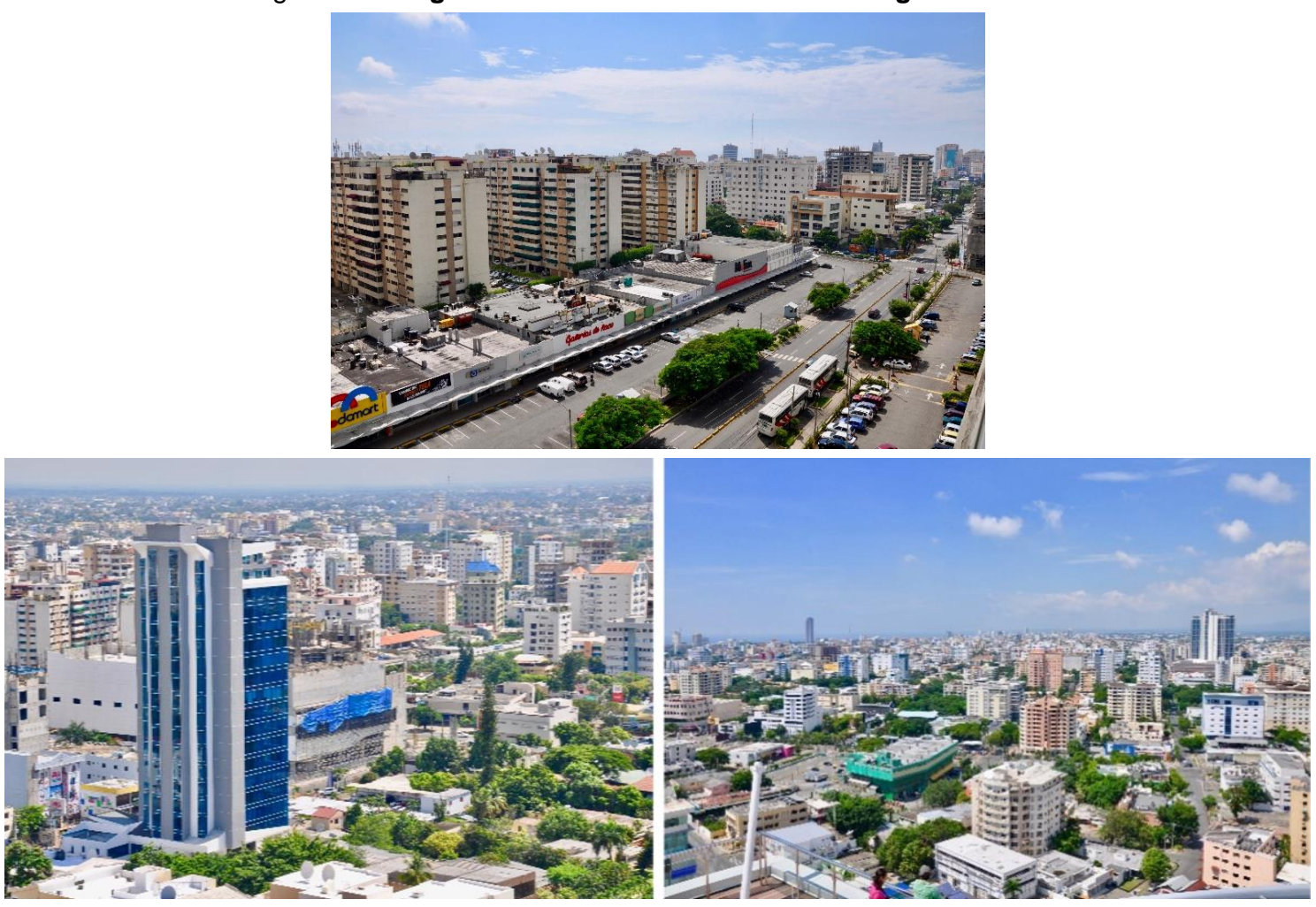

Fuente: Elaboración propia.

Ya desde hace unos años el arquitecto Omar Rancier, encargado actualmente del Departamento de Formulación de Política y Planes de ordenamiento y Desarrollo Territorial había realizado varios escritos referentes a este crecimiento, intervención y desarrollo urbano (Rancier, 1997b, 1997a, 1997c, 1998a, 1998b), entre ellas podemos resaltar Desniveles, urbanismo y concertación (Rancier, 1997b) donde explica más ampliamente estas intervenciones. En estas imágenes se puede apreciar la alta densidad edificatoria, versus el porciento de verde. 


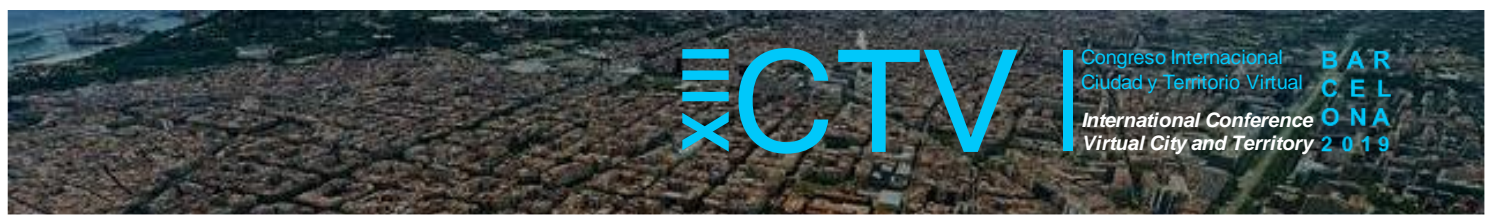

\subsection{Correlación de las variaciones de temperatura y el crecimiento urbano}

Evaluado el crecimiento urbano de la ciudad y las intervenciones realizadas en la misma se pueden correlacionar las intervenciones realizadas con las variaciones en las temperaturas evaluadas anteriormente. Desde el año 1997 se comenzó a percibir un incremento en la temperatura mínima. A partir de este año se aprecia variaciones cada vez más constante en la temperatura mínima. Estas fluctuaciones van de la mano con la época en que se realizaron las intervenciones urbanas para la avenida 27 de febrero. Para el año 1999 se inaugura el Bulevar 27 de febrero en conjunto con otras obras que se realizaron en el gobierno del Dr. Leonel Fernando (1996-2000).

A partir del año 2001 se pude apreciar cada vez más fluctuaciones mayores en la temperatura mínima en relación a las anteriores. Para el año 2005 se aprecia un resultado mayor de estas fluctuaciones ya que se registraron aumentos en la temperatura máxima. Para la intervención de la Avenida 27 de febrero. En este mismo periodo se inició el llamado "Boom de las torres" que se ha ido desarrollando paralelamente a las intervenciones urbanas hechas por el Estado. Este fenómeno aún sigue en desarrollo, cada año aumenta las construcciones de este tipo de edificaciones, generando la eliminación de espacios verdes donde había viviendas de dos niveles máximo con un gran porciento de áreas verdes (jardines y patios) pertenecientes a estas viviendas. La masificación de compra y venta de estas viviendas para construir edificaciones de altura, genera un incremento considerable del nivel de pavimentación a nivel urbano.

Figura 16. Imágenes de la ciudad de Santo Domingo, 1942 y 1943

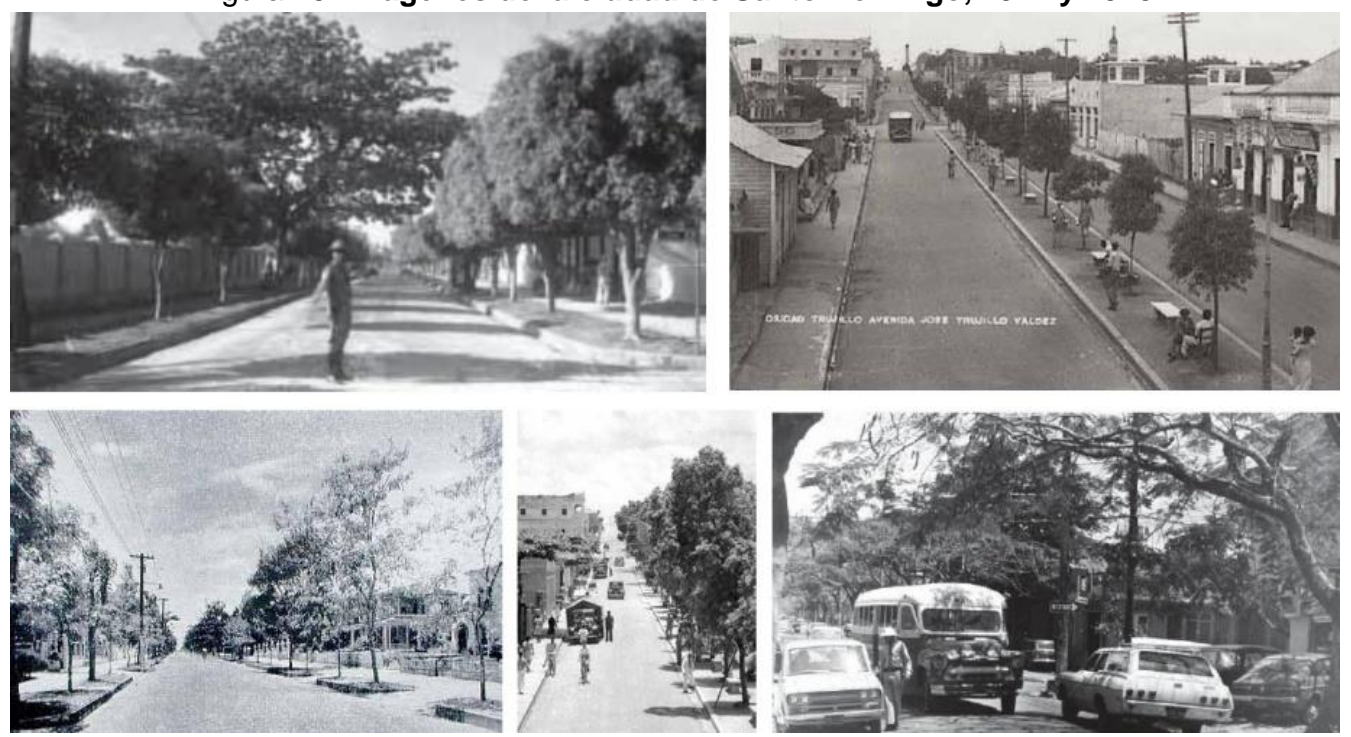

Fuente: Archivo General de la Nación. Los Árboles de Santo Domingo (Agencia de Cooperación Internacional de Japón (JICA) et al., 2010).

Para el año 2011 se inaugura el corredor Duarte, años previos durante su construcción se aprecia una fluctuación mucho mayor en las temperaturas máximas y mínimas. El incremento de intervenciones urbana ha aumentado, y por ende el porciento de hormigón, asfalto y otros materiales y paralelamente la disminución de la vegetación. 


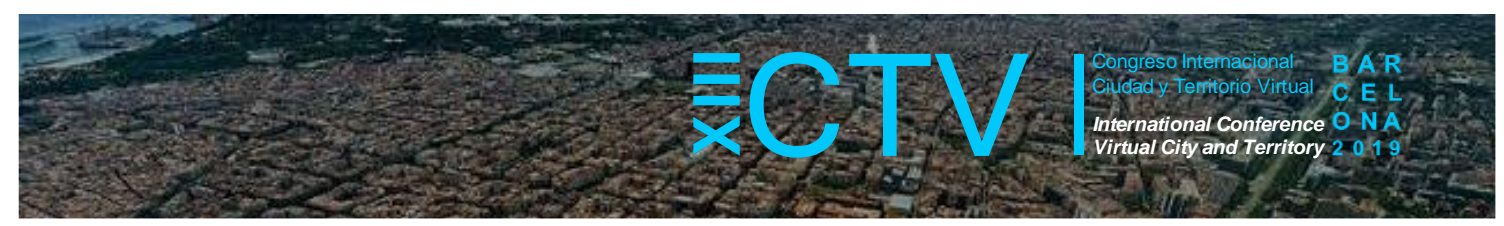

A raíz de todas estas intervenciones el incremento de este fenómeno es cada vez mayor. Las temperaturas mínimas presentan un aumento muy significativo cada año como igualmente las temperaturas máximas. Para el año 2017 la temperatura mínima y máxima ya reflejan un aumento de hasta $1.5^{\circ} \mathrm{C}$. El aumento de estas superficies urbana en hormigón y asfalto, conjugado con una disminución considerable de vegetación aporto al aumento del fenómeno de la isla de calor urbana.

El aumento de temperaturas cada vez se percibe más en la ciudad. En la Figura 16 se puede apreciar las calles de la ciudad de Santo Domingo entre el año 1942 y 1943 (Agencia de Cooperación Internacional de Japón (JICA), Instituto Tecnológico de Santo Domingo (INTEC), \& Ayuntamiento del Distrito Nacional (ADN), 2010), se puede apreciar el nivel de frondosidad de las calles como la densidad urbana en ese momento.

\section{Conclusiones}

Definitivamente Santo Domingo es hoy más caliente que hace 20 años, sobre todo en invierno, pero en otras estaciones también. Hemos encontrado que existe una correlación entre las fechas donde las temperaturas comenzaron a incrementarse y las intervenciones urbanas.

Para que las temperaturas promedio se hayan incrementado entre $0.80 \mathrm{C}$ y $1.5 \circ \mathrm{C}$ significa que las temperaturas que se registraron a lo largo de los días en las diferentes estaciones el año sufrieron aumentos significativos.

Las estaciones del año de otoño e invierno actualmente presentan temperaturas mayores a las que típicamente se acostumbra para este clima, es decir ya el otoño y el invierno no son tan frescos como solían ser años atrás.

Posiblemente, así como ha variado las estaciones del año que eran las épocas más frías, a su vez se verán afectadas las temperaturas máximas a futuro, reflejando unas primaveras y veranos con temperaturas aún más altas que las que ya se percibe. Comprobando las afecciones pronosticadas debido al cambio climático.

Las afecciones pronosticadas por el cambio climático ya se están viendo reflejadas en la ciudad con un aumento de hasta $1.5^{\circ} \mathrm{C}$ de la temperatura promedio.

El crecimiento descontrolado de la ciudad se ha reflejado en el aumento de superficies impermeables aportando al fenómeno de la isla de calor urbano, esto sumado a la pérdida en un alto porcentaje del arbolado existente en los patios y jardines de las casas individuales que pasaron a ser edificios de apartamentos en altura.

Las proyecciones nos indican que en los próximos 20 años este fenómeno de incremento de las temperaturas promedio se duplicará.

Se deben ir implementando herramientas para la adaptación y mitigación de los efectos al cambio climático en la ciudad. Asociado a esos efectos se presentan tormentas con mayor frecuencia que antes, con las consiguientes inundaciones urbanas, o sequías prolongadas. 


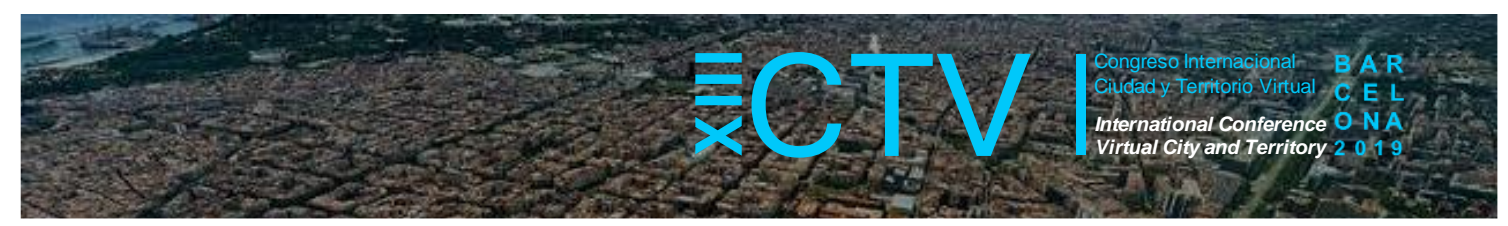

Las temperaturas mínimas han sido la herramienta de alerta de que se está produciendo un cambio en la temperatura, reflejando sus fluctuaciones a largo plazo en la temperatura máxima.

La existencia de normativas para el control de la densidad y altura edilicia que han sido establecidas sin una base científica, ha sido dos elementos que han aportado al fenómeno. Por otro lado, la pérdida de arbolado y el cambio en el tipo de arbolado que se debe usar en el entorno urbano de la ciudad de Santo Domingo, es el otro factor que hemos encontrado que contribuye también con los incrementos de temperatura que hemos encontrado entre $1995 \mathrm{y}$ el 2018.

Contribuciones de los autores: El primer, segundo y tercer (el tercer autor es estudiante de la carrera de arquitectura) autor han desarrollado la recolección de datos urbano y climáticos de la ciudad de Santo Domingo. Igualmente, han realizado una síntesis histórica y climática. El cuarto autor en conjunto con el primer y segundo autor han analizado y correlacionado el comportamiento de la temperatura y el crecimiento urbano de la ciudad. En conjunto se ha desarrollado las conclusiones obtenidas en base a las discusiones realizadas sobre los datos.

Conflicto de Intereses: Los autores declaramos que no existe conflicto de intereses.

\section{Bibliografía}

ADN. (2019). Ayuntamiento del Distrito Nacional. Santo Domingo, República Dominicana.

Agencia de Cooperación Internacional de Japón (JICA), Instituto Tecnológico de Santo Domingo (INTEC), \& Ayuntamiento del Distrito Nacional (ADN). (2010). Los Árboles de Santo Domingo. Retrieved from http://www.adn.gob.do/joomlatools-files/docman-files/Arboles de Santo Domingo INTEC JICA ADN 2010 AR(2).pdf

CEPAL, \& ONU. (2016). Agenda 2030 y los Objetivos de Desarrollo Sostenible Una oportunidad para América Latina y el Caribe. Santiago.

Garcia-Nevado, E., Pages-Ramon, A., \& Coch, H. (2016). Solar access assessment in dense urban environments: The effect of intersections in an urban canyon. Energies, 9(10). https://doi.org/10.3390/en9100796

López-Ordóñez, C. F., Roset, J., \& Rojas-Cortorreal, G. (2017). Análisis de la radiación solar directa en las calles de barcelona, en base a la relación entre su morfología y vegetación. Architecture, City and Environment, 12(34), 45-68. https://doi.org/10.5821/ace.12.34.4708

Masoud, B., Beckers, B., \& Coch, H. (2016). Sky Access versus Shading for Pedestrian Comfort in the Hot Tropical Climate of Jeddah. In First International Conference on Urban Physics (FICUP) (pp. 26-30). Galapagos: FICUP.

Oficina Nacional de Estadistica (ONE). (2009). Distrito Nacional en Cifras. Perfil Sociodemografico provincial. Santo Domingo: ONE.

Oficina Nacional de Estadistica (ONE). (2015). Expansión Urbana de las Ciudades Capitales República Dominicana 1988-2010. Santo Domingo. 


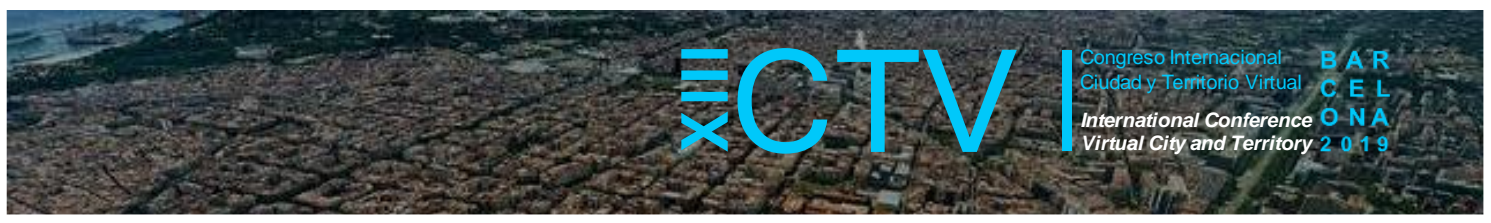

Oficina Nacional de Estadistica (ONE). (2016). Estimacion y proyección de la poblacion total 2000_2030. Santo Domingo, República Dominicana. Retrieved from https://www.one.gob.do/demograficas/proyecciones-de-poblacion

Oficina Nacional de Meteorologia (ONAMET). (2019). Datos meterologicos desde el año 1995 hasta el 2018. Santo Domingo, República Dominicana: ONAMET. Retrieved from http://onamet.gob.do/

Rancier, O. (1997a). ¿Que esperar del '98? Periodico El Siglo, $12 \mathrm{D}$.

Rancier, O. (1997b). Desniveles, urbanismo y concertación. Periodico El Siglo, 10D.

Rancier, O. (1997c). Espacio urbano. Periodico El Siglo, 10D.

Rancier, O. (1998a). De Fritz Lang a la 27 de Febrero: La metropoli como modelo. Periodico El Siglo, 8D.

Rancier, O. (1998b). La ciudad desde arriba. Periodico El Siglo, 10D.

Rojas-cortorreal, G., Navés, F., Peña, J., Roset, J., \& López-ordóñez, C. (2017). Climate and Urban Morphology in the City of Barcelona: The Role of Vegetation. In B. Fuerst-Bjelis (Ed.), Mediterranean Identities - Environment, Society, Culture (1st ed., p. 426). Croatia: InTech. https://doi.org/10.5772/intechopen.69125

Rojas Cortorreal, G. M. (2016). Cuantificación de la mejora de las condiciones ambientales producida por el arbolado urbano "Caso de estudio Barcelona, España y Santo Domingo, República Dominicana. Universidad Politecnica de Catalunya. Retrieved from http://www.tdx.cat/handle/10803/404744

Rojas Cortorreal, G. M., Roset, J., \& Navés, F. (2016). Contributions to micro climate comfort of tree species Platanus x hispanica. Jornada de Investigadores Predoctorales Interdisciplinaria (JIPI). https://doi.org/10.13140/RG.2.1.2786.0248

Salvati, A. (2016). La città compatta in clima Mediterraneo: isola di calore, morfologia e sostenibilità. Retrieved from http://www.tdx.cat/handle/10803/394047?locale-attribute=en

Salvati, A., Coch, H., \& Cecere, C. (2014). Which climate for each urban context? A preliminary comparative study on urban climate prediction and measurement in different districts in Rome and Barcelona . In Word Renewable Energy Congress XIII. https://doi.org/10.13140/RG.2.1.4777.3207

Salvati, A., Coch, H., \& Cecere, C. (2015). Urban Morphology and Energy Performance: the Direct and Indirect Contribution in Mediterranean Climate. In PLEA.

Sosa, M. B., Correa Cantaloube, E., \& Cantón, M. A. (2017). Forma urbana y comportamiento térmico exterior. Estudios Del Hábitat, 15(2), 025. https://doi.org/10.24215/24226483e025

Valdez, C. (2015). Historia crítica de la ciudad de Santo Domingo. (Publicaciones UNPHU, Ed.) (Publicacio). Santo Domingo, República Dominicana: Publicaciones UNPHU. 